$$
\text { 大学化学 }
$$

Univ. Chem. 2021, 36 (9), 2101028 (1 of 5)

•教学研究与改革・

doi: 10.3866/PKU.DXHX202101028

www.dxhx.pku.edu.cn

编者按: 分析化学是化学及相关学科的一门专业基础课程, 通过本课程的学习, 可以系统地掌握获取物质化学组成、 含量、状态信息的基本原理、基本理论、基本概念、基本知识、基本操作和基本技能，建立起认识物质的严格的 “量” 的概念, 养成实事求是的科学态度和严谨的科学作风, 提高分析、解决问题的能力, 为相关专业核心课及其专业选 修课打好基础。

目前分析化学课程的教学面临着不小的挑战: 分析化学教材内容编撰的挑战性; 分析化学课程教学的系统性; 各类概念、定义的准确性及其与其他课程的一致性; 相关理论的合理选择与摈弃, 做到与时俱进、将世界范围内最 新的科研成果及应用引入到教学过程中; 课程内容难度的选择; 传统理论的现代语言表述; 分析化学实验教学内容 的创新及有效改革等等。这些方面都十分值得广大分析化学及相关课程教师的探究。

《大学化学》编辑部组织了 “分析化学课程与实验教学” 专刊, 希望能通过大家的分享和探讨, 推动和促进对分 析化学课程与实验的教学改革。

\title{
研究生现代光谱分析课程的教学改革探索与实践
}

宦双燕”，宋国胜 ${ }^{*}$, 陈婷婷，王玉枝

湖南大学化学化工学院, 长沙 410082

摘要: 在现代光谱分析研究生课程的教学中, 围绕综合素质能力培养, 不断探索课程建设与教学改革的有效措施: (1) 教学内容与时俱进, 体现课程的科学性和前沿性; (2) 围绕立德树人目标设计课程思政案例, 加强 “三观” 价值 引领; (3) 探索翻转课堂教学、项目式教学, 运用智慧教学工具管理教学过程, 构建多元化考核评价体系。

关键词：现代光谱分析；课程思政；翻转课堂；项目式教学；多元化评价

中图分类号: G643; O6

\section{Exploration and Practice on Teaching Reform of Modern Spectral Analysis for Postgraduates}

\author{
Shuangyan Huan *, Guosheng Song *, Tingting Chen, Yuzhi Wang \\ College of Chemistry and Chemical Engineering, Hunan University, Changsha 410082, China.
}

\begin{abstract}
The teaching of the modern spectral analysis course focuses on the cultivation of the comprehensive quality and ability of postgraduate students, and constantly explores how to carry out the course construction and teaching reform to achieve the course objectives: (1) We keep pace with the times and constantly update the teaching contents to reflect the scientific and cutting-edge nature of the course. (2) We integrate the ideological and political elements into the course of the modern spectral analysis to help the guidance on moral values of the graduate students. (3) We constantly innovate our teaching methods and explore flipped class, project-based learning, using intelligent teaching tools to manage teaching progress and construct diversified assessment methods.
\end{abstract}

收稿: 2021-01-13; 录用: 2021-03-02; 网络发表: 2021-03-18

“通讯作者, Emails: syhuan@hnu.edu.cn (宦双燕); songgs@hnu.edu.cn (宋国胜)

基金资助: 2019 年湖南省研究生优质课程(现代光谱分析)立项项目；2020 年湖南省普通高等学校课程思政建设研究项目(HNKCSZ-2020-0074) 
Key Words: Modern spectral analysis; Course ideology and politics; Flipped class;

Project-based learning; Diversified assessment

研究生教育为高层次人才培养和创新创造能力提升提供重要保障, 如今中国特色社会主义进入 新时代, 科技发展和社会进步对高层次创新人才的需求更加迫切, 研究生教育的地位和作用进一步 彰显。当今化学学科的发展呈现交叉融合纵深发展的特点, 强调内涵式高质量发展, 如何结合学科 特色, 为国家培养德才兼备、创新能力突出的新时代研究生也是研究型高校肩负的历史使命。而课 程教学是研究生创新能力培养和 “三观” 价值引领的切入点和关键环节。如何将研究生素质能力培 养落实到每门研究生课程的建设中, 在课程教学中体现知识、素质和能力培养, 突出创新思维引导 和 “三观” 价值引领, 构建适应新时代的研究生课程教学体系和教学模式, 也是提高研究生人才培 养质量的有效途径 ${ }^{[1]}$ 。

以本教学团队开设的现代光谱分析研究生学位基础课为例。该课程是针对湖南大学化学学科硕 士研究生开设的一门专业基础必修课。该课程旨在介绍常用的光谱分析理论及最新的研究方法和技 术, 特别是尚未进入经典教科书的新方法, 对研究生从事光谱分析等领域研究工作起到引导作用。通 过本课程的学习, 培养研究生的科研创新思维和学术交流能力, 提高研究生运用所学现代光谱分析 技术解决实际科研问题的能力。本课程自2010年开设以来, 不断进行课程建设与教学改革探索, 2020 年获批湖南省研究生优质课程立项建设。本文主要对现代光谱分析课程建设与教学改革措施及成效 进行总结梳理。

\section{1 教学内容上与时俱进}

针对现代光谱分析课程, 国内外还没有合适的参考教材, 早期该课程的研究生教学结合了湖南 大学分析化学学科特色, 主要围绕激光光谱分析法、圆二色性法、表面等离子体共振技术、光化学 与生物传感器等内容开展教学。随着光谱分析领域相关分析技术的发展变革, 在教学内容上做出了 相应调整, 2013年以来主要围绕苂光共振能量转移、上转换发光、表面增强拉曼和表面等离子体共 振等现代分析技术及其在化学生物分析中的应用开展教学。随后2014年依托湖南大学研究生全英文 课程建设项目, 对课程教学内容和网站进行了全面建设。近年来随着光谱分析新方法的不断出现, 现 代光谱分析课程教学团队在光谱分析基本方法原理的基础上, 围绕科研前沿领域进行相关内容的拓 展, 目前32学时课程主要内容包括三部分: (1) 荧光光谱分析基本原理、共振能量转移(FRET)和上 转换发光原理及应用; (2) 拉曼光谱、表面增强拉曼光谱(SERS)和表面等离子共振(SPR)原理及应用; (3) 现代光谱分析新方法及应用, 主要介绍光声和近红外II区成像分析, 化学发光、生物发光和长余 辉发光分析等现代光谱分析新技术。

在教学中注重科研前沿文献、英文教材章节与教学的结合。在荧光光谱分析原理、FRET、SERS 等内容讲授时, 结合英文原版书籍的部分章节内容 ${ }^{[2]}$, 作为拓展学习资料。结合经典英文文献进行 方法技术的应用讲解, 在教学中将教师的最新研究成果融入到课程教学中, 如光声和近红外II区成 像、化学发光等内容, 均有教师课题组最新研究成果的介绍 ${ }^{[3-7]}$ 。在此基础上, 让学生围绕专题进行 科研前沿代表性英文文献的搜集和讲解, 将最新文献内容作为课程教学内容的一个重要组成部分, 依 此加强学生理论与实际应用相联系的能力, 拓展学科视野。

\section{2 课程思政案例设计与融入}

新时代高等教育的根本任务是立德树人, 这对研究生课程的育人功能也提出了新要求 ${ }^{[8]}$ 。如何 让课程在知识传授的同时, 发挥同向同行的协同效应, 在研究生培养中起到 “三观” 价值引领作用, 也是我们深入思考的问题。研究生不仅要掌握扎实的现代光谱分析专业知识, 还应具备家国情怀和 科学素养、国际视野和创新思维、合作意识和社会责任感。在现代光谱分析课程的教学中, 本教学 
团队不断挖掘课程蕴含的独特育人素材, 探索将其融入现代光谱分析课程的教学中。

在绪论部分, 以 “葡萄糖” 为关键词构建了一个立体化教学案例 ${ }^{[9]}$, 在教学中我们进一步将思政 元素与教学内容进行深度融合。该案例涉及到七个具体问题的学习和讨论：(1) 葡萄糖的来源与酶 反应; (2) 葡萄糖的吸收与转运蛋白; (3) 苂光标记观察葡萄糖转运蛋白; (4) 血糖水平与糖尿病; (5) 血糖计的检测原理; (6) 血糖的无创检测技术; (7) 血糖研究的前沿—智能调控。通过该案例, 学习如何从 “葡萄糖分子” 的 “点” 出发, 由 “点” 到 “面”, 纵深拓展的科学思维方式, 从宏观代 谢延伸到微观分子转运和疾病成因, 从健康相关的血糖检测拓展到微创、无创诊断和分子诊疗等科 研前沿问题。在该绪论教学中还设计了以下思政点: (1) 科研人物与科学家精神的介绍, 例如如何将 荧光蛋白变成 “工具” 来 “照亮” 细胞的华人诺奖得主钱永健先生。(2) 科技创新的国际形势与我国 实情比较, 激发科技强国情怀, 如传感器市场规模2015年已经达到1200亿, 而我国本土传感器产业 相对弱小, 在以 “智能制造” 为代表的第四次工业革命中, 加强传感器的研发, 实现 “中国智造” 是科技强国的必经之路。(3) 对客观事物内在本质、规律的归纳提炼, 如血糖研究可以总结出从有创 到无创, 从静态到动态监测, 从检测到诊疗一体化的普遍规律, 这一规律适用于生命体系其他相关 分子的科学研究。(4) 科研伦理思辨的引入, 如关于 “葡萄糖” 隐形眼镜功能的拓展研发, 采用内置 摄像头眨眼控制开关和存储, 是否涉及隐私侵犯和社会安全问题? (5) 科研创新思维的训练, 如血 糖相关的诊疗研究中, 介绍可监测并调节血糖水平的石墨烯腕带、智能胰岛素诊疗贴片、“生物纹身” 式比色传感器、体内生物燃料电池驱动的葡萄糖传感器等, 引导学生如何打破思维定式, 产生创新 思想。学习该课程的研究生正处于开题阶段, 对如何选择课题开展研究存在一定的迷茫, 采用该案 例也可进一步指导学生如何将个人科研选题与 “面向人民生命健康” 的国家战略相结合, 寻找科研 创新点。

在讲授荧光共振能量转移(FRET)时, 插入诺奖得主下村修先生关于海萤虫发光机理和绿色荧光 蛋白的研究案例。如何从海萤中提取发光物质是美国科学家长期研究没有解决的难题, 下村修经过 不解努力终于寻找到特殊的方式结晶出海萤荧光素。他也因此获得去美国普林斯顿大学约翰逊实验 室进一步研究水母发光机理的机会。后来的研究表明, 海萤虫发光是荧光素在苂光素酶催化下产生 的生物发光, 而水母发光机理完全不同。经过几年的努力, 下村修从水母体内提取了一种光敏的水 母蛋白, 发现它与钙离子结合时可以发出蓝光, 这与水母发出的绿光还不一致, 又经过几个月的不 解努力, 他又提取出了绿色荧光蛋白(GFP), 正是GFP与水母发光蛋白复合, 吸收了蓝光, 进一步释 放出绿光来, 而这个反应正是荧光共振能量转移(FRET), 他在1974年终于阐明了水母的发光机理。 该案例不仅与FRET知识点阐释密切相关, 还具有可拓展探究的科学精神和价值观内涵。下村修少年 时期受原子弹爆炸的核辐射伤害, 一生遭受病痛折磨, 与其他人相比他也没有耀眼的学历和科研特 长, 只是一位普通实验人员, 但这些从未成为他在科研成长道路上的绊脚石, 正是这份对科研的热 爱和执着, 让他从一个门外汉最终走上诺贝尔奖的殿堂。下村修的科研经历也体现了科学研究的特 点, 多数情况下既定研究目标和实际研究结果并不一致, 遇到失败和挫折时, 不轻言放弃才有可能 找到有意义的突破口。真正的科学家是不为名利所动, 甘于长期艰苦的科研探索, 水母发光蛋白和 GFP发现的前后 30 年, 不仅未被重视, 反而受到很多质疑, 下村修直到 80 岁获得诺贝尔奖前依然是 寂寂无名的。而GFP真正实现其有意义的应用, 是经历了几代人的共同努力。90年代, 马丁.查尔菲 在大肠杆菌等原核生物中成功表达了 GFP, 表明GFP可以作为各种生物体发光基因标签的价值。而后 钱永健对GFP进行了有效改造, 增强它的发光效率, 把它由绿色变成了多色, 荧光蛋白才真正成为 细胞和活体标记的分子工具, 得到广泛应用和认可。因此, 下村修、马丁.查尔菲和钱永健三人共同 获得了 2008 年的诺贝尔化学奖 ${ }^{[10]}$ 。通过对该案例的解读, 不仅加强了学生对FRET知识点的深入理 解, 还引导他们对科学家精神和科研价值观进行深入思考。

在讲解基于FRET的核酸探针设计时, 则结合2020年新冠肺炎疫情的实际情况, 引入当前新冠病 毒核酸检测常用技术—-RT-PCR苂光探针法, 介绍如何进行咽拭子等方式取样, 如何提取纯化病毒 
RNA, 如何将病毒RNA反转录成互补的 $\mathrm{CDNA}$ 链, 再以 $\mathrm{cDNA}$ 链为基础进行PCR扩增和定量分析。在 方法的介绍中, 引导学生思考取样和纯化的风险、大规模核酸检测的难点、假阳性的可能原因等问 题。从这些问题让学生设身处地地去思考作为医务人员如何克服风险、极端环境、长时间工作等困 难, 完成从疫情爆发初期到进入疫情防控常态化的核酸篎查工作; 我们的国家把人民生命安全和身 体健康放在第一位, 采用了最全面最严格最彻底的防控措施, 才能迅速在一个月初步遏制疫情蔓延 势头, 两个月左右将本土每日新增病例控制到个位数, 用三个月的时间取得武汉保卫战、湖北保卫 战的决定性成果。同时引导学生思考目前核酸检测方法存在的缺点和解决途径, 再引入我校谭蔚泓 院士带领的研究团队在疫情防控初期, 如何投入新冠病毒核酸现场快速检测产品的研发, 体现出基 础科研创新对疫情防控的科研支撑作用。

在课程教学中还梳理了其他类型的思政素材案例, 如: (1) Raman光谱的发现与科学家精神; (2) 公共安全与社会责任感相关案例, 如SERS技术与农药兽药残留检测、毒品检验、指纹鉴定等;

（3）健康中国战略相关案例, 如分子探针在精准成像与诊疗中的应用; (4) 理论联系实际的案例, 如 现代光谱分析技术在食品安全、环境监测、医疗诊断、生产过程监测等领域的应用实例; (5) 绿色化 学相关案例, 如长余辉发光与绿色光源; (6) 以本课题组研究生探索创新研究的经历、心得, 指导研 究生如何树立远大的科学抱负, 并脚踏实地地开展科研创新工作; (7) 以 “违反学术诚信的案例”, 讲述坚持科研诚信和恪守学术道德的重要性。

\section{3 教学方式不断革新}

在现代光谱分析的课程教学中, 根据课程特点并总结以往教学经验的基础上, 不断探索教学方 式上的革新。近年来主要开展了以下方面的探索:

(1) 翻转课堂教学实践

研究生的学习不仅仅是基本的原理方法, 需要结合大量文献阅读, 总结出该领域的研究进展, 加强对技术创新应用的理解。在现代光谱分析的教学中, 采用翻转课堂教学来实现该能力的培养。

围绕课堂讲授过的现代光谱分析基本原理, 选择与课程内容相关的一个具体课题, 查阅最近 5 年 的高水平文献, 制作该课题的汇报课件, 汇报内容包括基本原理简介、领域进展、代表性文献精讲 和总结。

以长余辉发光为例, 其中一组同学选择了 “长余辉纳米材料的研究与应用” 课题, 他们分工合 作制作了翻转课堂讲解的内容。首先对长余辉纳米材料的分类、发光机理、合成方法和应用领域进 行了概述, 在此基础上围绕余辉增强方法、生物传感应用、肿瘤诊断治疗、靶向生物成像、光催化 降解五个方面进行文献拓展介绍。课堂教学中, 第一次课就将翻转课堂的教学方式和分组要求告知 学生, 在基本原理方法的讲解过程中, 学生开始进行文献查阅、讨论和课件制作。翻转课堂汇报时, 要求每位同学都参与讲解, 这样不仅锻炼了研究生的英文文献查阅和归纳总结能力, 还进一步锻炼 了文献汇报和科研思路梳理能力。部分优秀作品制作成讲解视频, 丰富了课程的教学资源。讲解结 束后, 其他组同学针对报告内容提问, 该组同学进行回答, 加强思考和互动。

(2) 项目式分组学习

教学中将学生分组, 每组选择一个与课程内容密切相关的课题, 形成一个小的项目组。在课程 学习和翻转课堂教学中, 均采用项目式分组学习的方式。教学班级通常为 60 人左右, 分为 12 个小组, 每组设一位组长, 通过分组讨论形成选题, 再进一步组间协调, 让课题选择不重叠, 并涵盖课程大 部分内容。如2020年选题有: FRET在生物传感方面的应用; 上转换发光探针的生物检测应用; SERS 探针在检测诊断方面的应用; 近红外小分子荧光染料研究进展及应用; 近红外光热和光动力肿瘤治 疗应用等。

组长负责项目进度, 组织讨论和协作, 对课题任务进行具体分工, 并督促组员的进展和汇总课 件。在课题汇报中, 体现每位组员的共同参与, 在提问环节, 组员们作为一个集体来共同参与问题 
回答。在课堂提问和课堂互动环节中, 也采用分组讨论的方式, 提交集体讨论得出的答案。通过项 目式分组学习, 加强了研究生之间的合作意识和团队观念。

(3) 运用智慧教学工具进行教学过程的管理

在现代光谱分析课程的教学中采用了中国大学MOOC平台的慕课堂智慧教学工具进行教学过程 管理。课前教师在该平台建课和备课, 学生通过微信扫描二维码或输入课堂码进入慕课堂。课前的 点名签到和预习小测验, 就可以采用慕课堂进行。课中回答问题、讨论互动和课后作业, 也可以采 用慕课堂进行, 提交后教师可以看到统计结果。对于翻转课堂的课题汇报讲解, 采用慕课堂打分和 投票的方式, 让每位同学参与为每组的报告打分, 并评选出最佳讲解员, 颁发电子奖状。另外利用 慕课堂的教学管理后台数据结果分析, 可以获得每位同学的课堂表现评价, 作为考核依据之一。

(4) 考核方式上的多元化

现代光谱分析课程的期末成绩由平时成绩(60\%)和期末考核 (40\%)两部分构成。平时成绩的100分 包括: 小组课题汇报互评(30分), 个人文献讲解(20分), 讨论互动情况(20分), 考勤(10分), 慕课堂练 习(20分)。这些成绩除讨论互动情况, 其他均根据系统后台数据和慕课堂中学生互评的数据来导入, 体现了多元化评价和过程考核的目的, 能够客观公平地体现每位学生的自主学习情况。期末考核内 容包括概念辨析、原理方法比较、对文献的分析归纳, 以及针对某些目标物分析, 结合所学光谱分 析知识进行创新方案设计等内容。考核的内容需要在理解原理的基础上进行深入探究, 题目的答案 具有开放性, 体现对研究生的能力培养。

\section{4 结语}

总之, 本教学团队将继续围绕湖南大学研究生培养目标和学位要求对现代光谱分析课程体系进 行设计和优化。以研究生能力培养为核心, 突出创新思维和能力, 拓宽知识面和国际视野, 注重 “三 观” 价值引领, 加强学术道德和科研诚信教育, 注重前沿引领和方法的传授, 强化研究生对创新过 程和创新思维的理解和训练。在课程的运行管理上进一步探索有效机制, 加强师生之间的交流互动, 鼓励研究生参与教学设计和教学改革, 参与建设和优化现代光谱分析的课程资源和网络平台, 实现 在线资源的共建共享, 激发学习兴趣, 加强自主学习, 重视知识获取、学术鉴别、独立思考、理论 联系实际和科研创新能力的培养。同时加强过程评价, 建立更为合理的考评机制。

\section{参 考 文 献}

[1] 新华社. 习近平: 把思想政治工作贯穿教育教学全过程. (2016-12-08) [2020-10-10].

http://www.xinhuanet.com//politics/2016-12/08/c_1120082577.htm

[2] Lakowicz, J. R. Principle of Fluorescence Spectroscopy, 3rd ed.; Springer Science: New York, USA, 2006; pp. $27-61$.

[3] Teng, L.; Song, G.; Liu, Y.; Han, X.; Li, Z.; Wang, Y.; Huan, S.; Zhang, X. B.; Tan, W. J. Am. Chem. Soc. 2019, 141 (34), 13572.

[4] Chen, T. T.; Yi, J. T.; Zhao, Y. Y.; Chu, X. J. Am. Chem. Soc. 2018, 140 (31), 9912.

[5] Wang, B.; Wang, Y.; Wang, Y.; Zhao, Y.; Zeng, Z.; Huan, S.; Song, G.; Zhang, X. Anal. Chem. 2020, 92, 4154.

[6] Zheng, X.; Peng, R.; Jiang, X.; Wang, Y.; Xu, S.; Ke, G.; Fu, T.; Liu, Q.; Huan, S.; Zhang, X. Anal. Chem. 2017, 89, 4154.

[7] Xu, S.; Liu, H. W.; Yin, X.; Yuan, L.; Huan, S. Y.; Zhang, X. B. Chem. Sci. 2019, 10, 320.

[8] 习近平. 在北京大学师生座谈会上的讲话. 人民日报, 2018-05-03 (2).

[9] 宦双燕, 王玉枝. 大学化学, 2018, 33 (4), 11.

[10] 丁滪. 科学, 2009, 61 (1), 49. 